\title{
Distribution of Heavy Metals and Other Components in the Various Size Fractions of House Dust
}

\author{
Christof Lanzerstorfer \\ Process Engineering and Production/University of Applied Sciences Upper Austria \\ Stelzhamerstraße 23, Wels, Austria \\ c.lanzerstorfer@fh-wels.at
}

\begin{abstract}
For the investigation of the distribution of heavy metals and other components in the various size fractions of house dust the dust sample was separated into size fractions by sieving and air classification. The analysis of the size fractions shows that the heavy metals and the other components are not uniformly distributed in the different size fractions. The highest total carbon (TC) concentrations were found in the size fractions with a mass median diameter of 18 to $95 \mu \mathrm{m}$, while in the coarser size fractions and in the finest size fraction the TC was lower. In contrast, for many heavy metals and other metals (e.g. Al, Fe, Mn, Ti, Ba, Sr, As, Cu, V) the maximum concentrations were found in the finest size fraction and with increasing size of the dust fractions the concentrations decreased. The distribution of $\mathrm{Zn}$ was different. In the four finest size fractions the concentration was nearly constant.
\end{abstract}

Keywords: House dust, dust composition, size distribution, heavy metals, air classification

\section{Introduction}

People spend approximately $88 \%$ of the time indoors in homes and offices [1]. Transport of particulate matter suspended in the atmosphere and soil adhering to footwear are the two main migration pathways of inorganic contaminants to indoors [2,3]. Activities carried out within the house, especially heating, may be an additional important source of contaminants. House dust is a heterogeneous mixture of organic and inorganic particles. The relation of inorganic and organic matter in house dust may vary in a wide range. A variation of the loss on ignition between 5\% and $95 \%$ has been reported [4].

Over the past decades, there has been increasing concern about exposure of people to indoor contaminants, especially because of the amount of time people spend indoors. Heavy metals exist to a certain level in the natural environment as trace elements in rocks and soils. However, they are released to the environment also from anthropogenic sources. They may originate from various sources, including traffic emissions and industrial sources. Related to their crustal abundances, heavy metals show considerable enrichment in indoor environments [5]. Values for the concentration of various heavy metals in house dust have been reported in various studies [6-10].

The particles of the dust vary in shape and size. The particle size ranges from $>2 \mathrm{~mm}$ to $<63 \mu \mathrm{m}$ [4]. The size dependence of the heavy metal concentrations is interesting, especially for the very small size fractions like the inhalable size fractions of dust (PM2.5 and PM10). Different methods for sampling house dust are described in the literature. The most common method used is vacuum sampling $[4,11]$.

In this paper the first results of a study are presented where the distribution of heavy metals in the various size fractions of house dust was investigated. For the separation of the house dust into size fractions conventional sieving as well as air classification had to be applied.

\section{Material and methods}

The study was performed in Wels, a mid-size town in Austria with approximately 60,000 inhabitants. The house dust samples were collected from the filter of a central vacuum cleaning system in a family house in the suburbs of Wels. The pipe network of the central vacuum cleaner system is made of plastics. Therefore, no contamination of the dust particles by erosion of pipe material has to be considered. Six persons live in the house and the floor area is $180 \mathrm{~m}^{2}$. The vacuum cleaner is used regularly for cleaning the wooden floors, carpets and the upholstered furniture. The whole dust content of the filter 
of the vacuum cleaner, accumulated in a period of approximately three months, was taken. The material was dried at $105^{\circ} \mathrm{C}$ for twelve hours.

In a first stage the dust was sieved with a $2.0 \mathrm{~mm}$ sieve. To separate the agglomerates of fibres and dust some rubber balls were used in the sieving procedure. However, there was still some fine dust in the fibre agglomerates. Therefore, the mass fractions of the various size fractions can be indicative only. In a second stage the material which passed through the $2.0 \mathrm{~mm}$ sieve was sieved using a sieve stack consisting of the following sieves: $500 \mu \mathrm{m}, 400 \mu \mathrm{m}, 315 \mu \mathrm{m}, 250 \mu \mathrm{m}$ and $200 \mu \mathrm{m}$. The passage of the $200 \mathrm{~mm}$ sieve was air classified into four size fractions. Because of some erosion of material on the classifier wheel the heavy metals contained in the wheel material $(\mathrm{Cr}, \mathrm{Ni}$ and $\mathrm{Mo})$ could not be investigated [12]. The particle size distribution of the size fractions was measured using a Sympatec HELOS/RODOS laser diffraction instrument with dry sample dispersion. The instrument was checked with a Sympatec SiC-P600'06 standard with a target value for the mass median diameter $\mathrm{d}_{50}$ of $25.59 \mu \mathrm{m}$. The measured value for the $\mathrm{d}_{50}$ was $25.62 \mu \mathrm{m}$.

All chemical analyses were measured in duplicate. For the heavy metals analysis the dust samples were dissolved by aqua regia digestion. The concentrations were measured by inductively-coupled plasma optical emission spectroscopy (Horiba Jobin Yvon Ultima 2). The concentration of alkali and earth alkali metals ( $\mathrm{Na}, \mathrm{K}, \mathrm{Mg}, \mathrm{Ca}$ ) was measured by ion chromatography using a Dionex ICS-1000 system. Details for the analytical method can be found elsewhere [13,14]. The total carbon (TC) content of the dust was determined using an Elementar Analysensysteme LiquiTOC system with a solids material extension.

\section{Results}

The mass fraction of the various size fractions of the house dust is given Table 1, together with the mass median diameter of the size fraction. The particle size distribution of the smallest size fractions produced by air classification is shown in Fig. 1.

Table 1: Mass fraction of the various size fractions.

\begin{tabular}{|c|c|c|c|c|c|}
\hline \multicolumn{3}{|l|}{ Sieving } & \multicolumn{3}{|c|}{ Air classification of fraction $<200 \mu \mathrm{m}$} \\
\hline Size fraction & $\begin{array}{l}\text { Mass } \\
\text { fraction }\end{array}$ & $\begin{array}{c}\text { Mass median } \\
\text { diameter in } \mu \mathrm{m}\end{array}$ & Size fraction & $\begin{array}{l}\text { Mass } \\
\text { fraction }\end{array}$ & $\begin{array}{c}\text { Mass median } \\
\text { diameter in } \mu \mathrm{m}\end{array}$ \\
\hline $500-400 \mu \mathrm{m}$ & $8.5 \%$ & 430 & & & \\
\hline $315-400 \mu \mathrm{m}$ & $11.9 \%$ & 340 & & & \\
\hline $250-315 \mu \mathrm{m}$ & $10.7 \%$ & 270 & & & \\
\hline $200-250 \mu \mathrm{m}$ & $6.3 \%$ & 220 & & & \\
\hline \multirow[t]{4}{*}{$<200 \mu \mathrm{m}$} & \multirow[t]{4}{*}{$62.6 \%$} & \multirow[t]{4}{*}{55} & Particle Class 4 & $25.3 \%$ & 95 \\
\hline & & & Particle Class 3 & $28.1 \%$ & 37 \\
\hline & & & Particle Class 2 & $7.3 \%$ & 18 \\
\hline & & & Particle Class 1 & $1.9 \%$ & 1.4 \\
\hline
\end{tabular}

The TC content of the house dust sample was $23.1 \%$. In a study the concentration of floor dust in offices was $33 \%$ [15]. Considering a mass fraction of carbon in the organic matter the TC content is in a similar range. The size dependence of the TC content is shown in Fig. 2. Generally, the TC content was significantly higher in the smaller size fractions with the exemption of the smallest fraction Particle class 1 (PC1). In this finest fraction with a mass median diameter of $1.4 \mathrm{~mm}$, the TC content was nearly in the same range as for the coarse fractions $>200 \mu \mathrm{m}$.

The average relative standard deviation calculated from the duplicate measurements was 9\%. Figure 3 and Figure 4 show the dependence of the concentrations on the particle size for the major components $\mathrm{Na}, \mathrm{K}, \mathrm{Mg}, \mathrm{Ca}, \mathrm{Al}$ and $\mathrm{Fe}$ and the minor components $\mathrm{Mn}, \mathrm{Ti}, \mathrm{Ba}$ and $\mathrm{Sr}$, respectively. For $\mathrm{K}, \mathrm{Al}, \mathrm{Fe}$ and $\mathrm{Ca}$ significantly higher concentrations were found for the finest size fractions. Within the coarser size fractions the concentrations did not vary very much. The minor components $\mathrm{Ba}, \mathrm{Mn}, \mathrm{Sr}$ and Ti showed a similar behaviour (Figure 4). In contrast, the concentrations of $\mathrm{Na}$ and $\mathrm{Mg}$ showed no distinct size dependence. 
Also the heavy metals are enriched in the finest fractions of the dust. For $\mathrm{Pb}, \mathrm{Co}$ and $\mathrm{V}$ the concentrations were higher, especially in the two finest size fractions PC 1 and PC 2, while the concentrations in the size fractions from PC 3 to $400-500$ were relatively constant (Fig. 5). The distribution of $\mathrm{Zn}$ and $\mathrm{Cu}$ was somewhat different. The $\mathrm{Zn}$ concentration was nearly constant for the four fine size fractions (PC 1 to PC 4). In the coarser size fractions the concentration varied but no distinct trend could be identified. And although the concentration of the $\mathrm{Cu}$ was typically higher in the fine size fractions, the concentration showed no distinct trend.

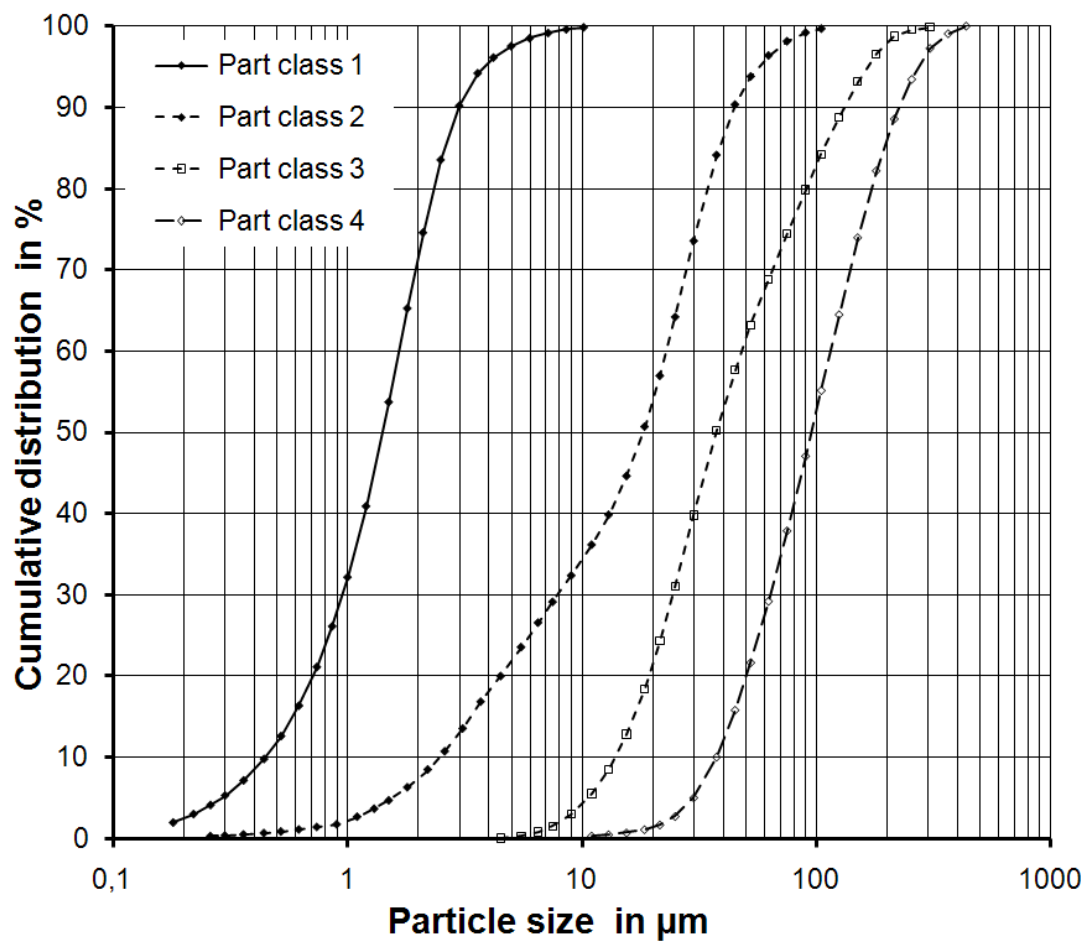

Fig. 1: Particle size distributions of the dust fractions produced from the dust passing the $200 \mu \mathrm{m}$ sieve.

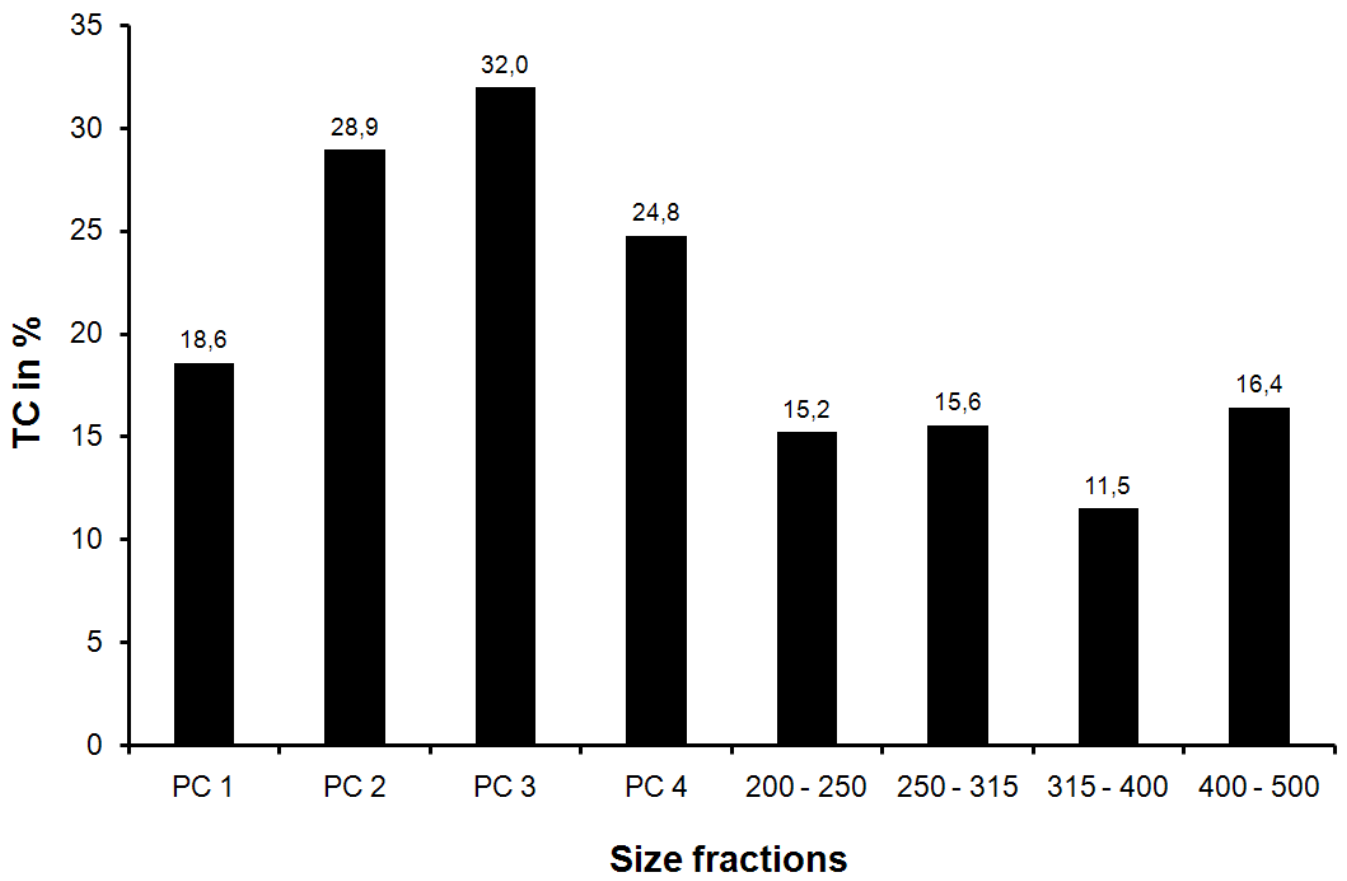

Fig. 2: Size dependence of the TC content. 


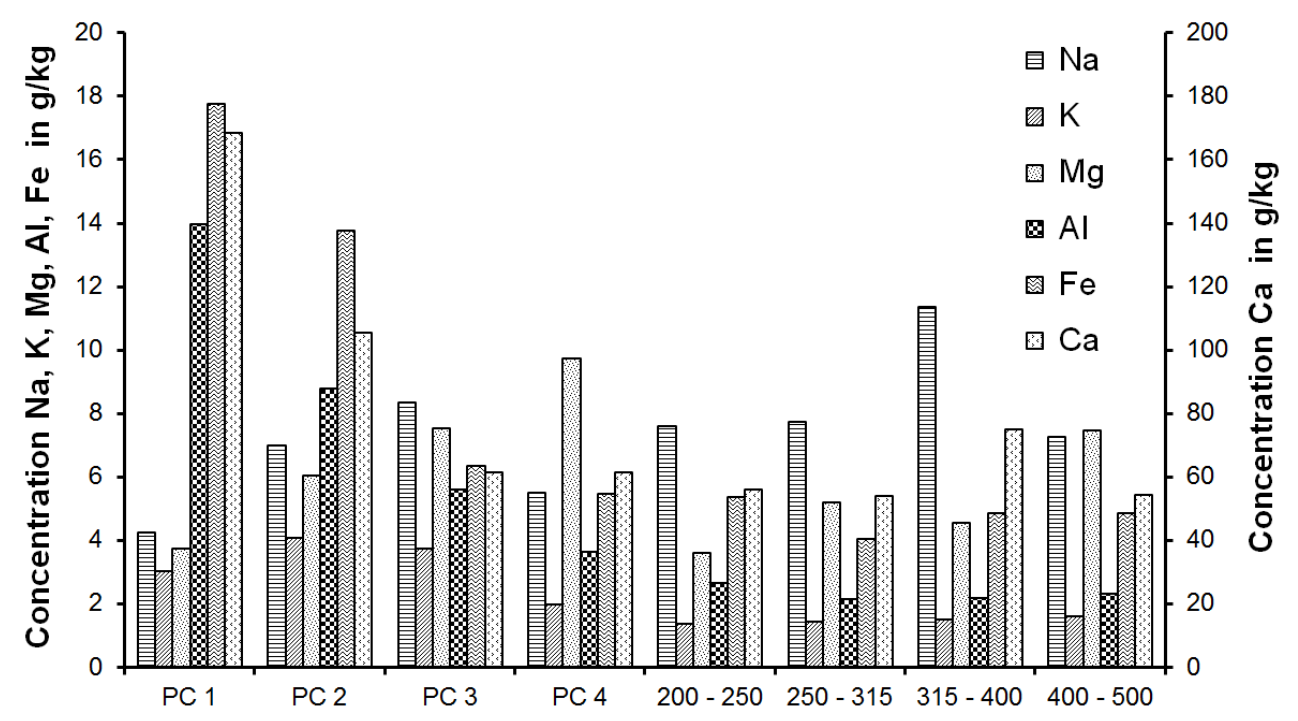

Fig. 3: Size dependence of the concentrations of $\mathrm{Na}, \mathrm{K}, \mathrm{Mg}, \mathrm{Ca}, \mathrm{Al}$ and Fe.

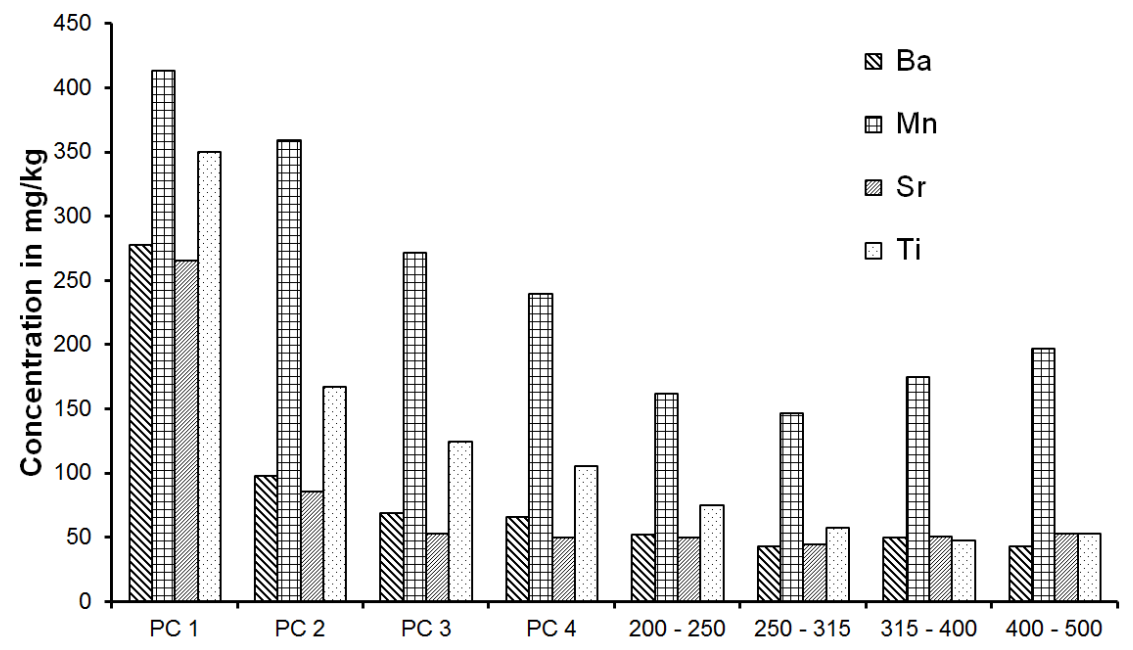

Fig. 4: Size dependence of the concentrations of Ba, Mn, Sr and Ti.

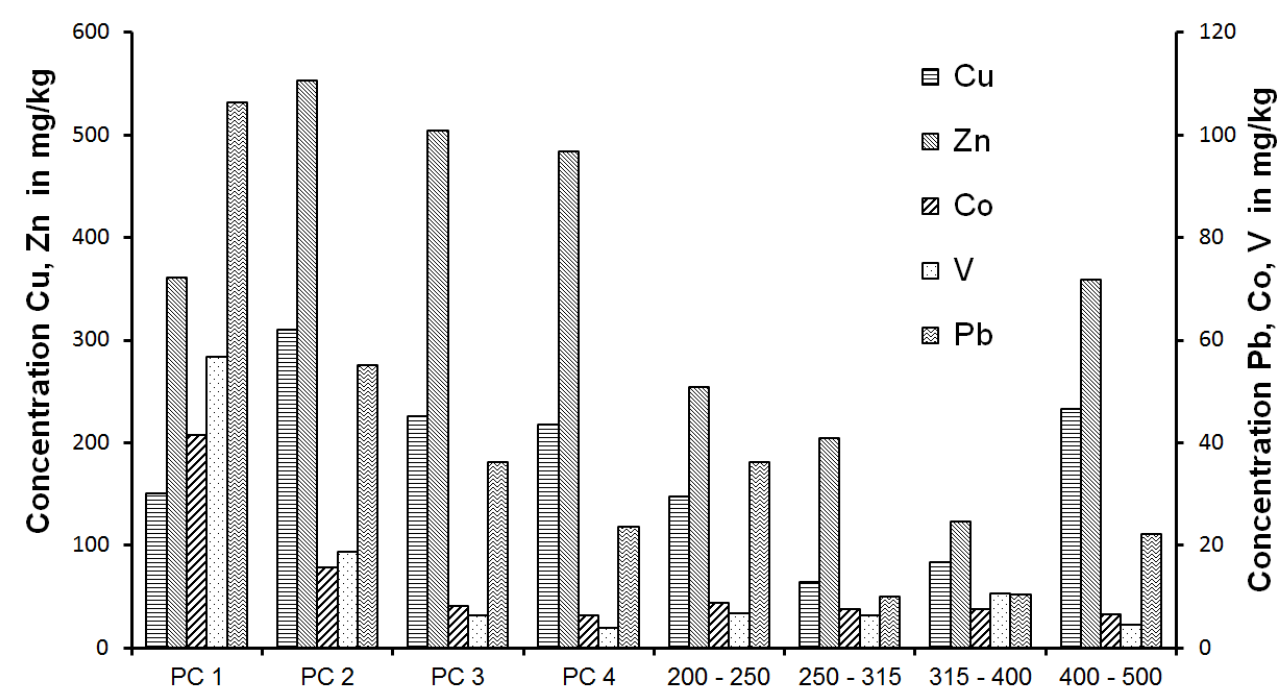

Fig. 5: Size dependence of the concentrations of various heavy metals. 


\section{Conclusion}

Heavy metals and other components are not uniformly distributed in the different size fractions of house dust. The TC content varied between $11.5 \%$ and $32 \%$. The highest concentrations were found in the size fractions with a mass median diameter of 18 to $95 \mu \mathrm{m}$, while in the finest size fraction the TC was lower. In contrast, for other metals like $\mathrm{Al}, \mathrm{Fe}, \mathrm{Mn}, \mathrm{Ti}$, $\mathrm{Ba}$ and $\mathrm{Sr}$ and the heavy metals $\mathrm{Pb}, \mathrm{Cu}$ and $\mathrm{V}$, the maximum concentrations were found in the finest size fraction. The distribution of $\mathrm{Zn}$ was different. In the four finest size fractions the concentration was nearly constant.

\section{Acknowledgements}

Proofreading by P. Orgill and laboratory work by M. Repolusk are gratefully acknowledged.

\section{References}

[1] US EPA, Exposure factors handbook. EPA/600/P-95/002Fa-c, Washington, DC: U.S. EPA National Center for Environmental Assessment, Office of Research and Development, 1997.

[2] A. Hunt, D. L. Johnson, and D. A. Griffith, "Mass transfer of soil indoors by track-in on footwear," Sci. Total Environ., vol. 370, no. 2-3, pp. 360-371, 2006.

[3] T. L. Thatcher and D. W. Layton, "Deposition, resuspension, and penetration of particles within a residence," Atmos. Environ., vol. 29, no. 13, pp. 1487-1497, 1995.

[4] W. Butte and B. Heinzow, "Pollutants in House Dust as Indicators of Indoor Contamination," in Reviews of Enviromental Contamination and Toxicology, vol. 175, G.W. Ware, Ed. New York: Springer, 2002, pp. 1-46.

[5] P. E. Rasmussen, "Can metal concentrations in indoor dust be predicted from soil geochemistry?" J. Anal. Sci. Spectrosc., vol. 49, no. 3, pp. 166-174, 2004.

[6] J. E. Fergusson and N. D. Kim, "The elemental composition house dust and street dust," Sci. Total Environ., vol. 100, no. 1 , pp. 125-150, 1991.

[7] J. E. Fergusson, E. A. Forbes, R. J. Schroeder, and D. E. Ryan, "The elemental composition house dust and street dust," Sci. Total Environ., vol. 50, no. 1, 217-221, 1985.

[8] G. Chattopadhyay, K. C.-P. Lin, and A. J. H. Feitz, "Household dust metal levels in the Sydney metropolitan area," Environ. Res., vol. 93, no. 3, pp. 301-307, 2003.

[9] P. E. Rasmussen, B. J. Subramanian, and B. J. Jessiman, "A multi-element profile of housedust in relation to exterior dust and soil in the city of Ottawa, Canada," Sci. Total Environ., vol. 267, no. 1-3, pp. 125-140, 2001.

[10] P. Karamelo, "Total and Extractable Heavy Metals in Indoor and Street Dust in Elbasan city, Albania," Int. J. Sci. Res., vol. 4, no. 2, pp. 133-139, 2015.

[11] T. Schneider, "Sampling of Surface Dust in Building," in: Indoor Environmrent: Airborne Particles and Settled Dust, L. Morawska and T. Salthammer, Eds. Weinheim: Wiley-VCH, 2004, pp 82-104.

[12] C. Lanzerstorfer, "Investigation of the contamination of a fly ash sample during sample preparation by classification," Int. J. Environ. Sci. Technol., vol. 12, no. 4, pp. 1437-1442, 2015.

[13] C. Lanzerstorfer, "Chemical composition and physical properties of filter fly ashes from eight grate-fired biomass combustion plants," J. Environ. Sci,. vol. 30, no. 1, pp. 191-197, 2015.

[14] C. Lanzerstorfer and M. Kröppl, "Air classification of blast furnace dust collected in a fabric filter for recycling to the sinter process," Resour. Conserv. Recycl., vol. 86, no. 1, pp. 132-137, 2014.

[15] L. Mølhave, T. Schneider, S. K. Kjærgaard, L. Larsen, S. Norn, and O. Jørgensen, "House dust in seven Danish offices," Atmos. Environ., vol. 34, no. 28, pp. 4767-4779, 2000. 